\title{
Responses of muscles of patients with Duchenne muscular dystrophy to chronic electrical stimulation
}

\author{
O M SCOTT, G VRBOVÁ, $\dagger$ S A HYDE, V DUBOWITZ* \\ From the Departments of Physiotherapy and Paediatrics, ${ }^{*}$ Hammersmith Hospital, and Department of \\ Anatomy and Embryology for Neuroscience, $†$ University College, London, UK
}

SUMMARY The effect of chronic low frequency stimulation on the tibialis anterior muscle of children with Duchenne muscular dystrophy was investigated. Baseline data from 16 boys established low values of maximum voluntary contraction which did not improve with age. Studies of the contractile properties revealed significant slowing $(p<0.001)$ of mean relaxation time compared to that of normal children's muscles. There was no loss of force during fatigue testing, as in normal children, but in contrast to normal children, there was no potentiation at lower frequencies of stimulation. Intermittent chronic low frequency stimulation of muscles in six young ambulant children with Duchenne muscular dystrophy resulted in a significant increase $(\mathrm{p}<0.05)$ in mean maximum voluntary contraction compared with the mean forces exerted by the unstimulated control muscles of the contralateral leg.

During development, mammalian skeletal muscle fibres undergo a considerable number of changes in the biochemistry of the muscle cell, ${ }^{1}$ which leads to histochemical maturation and differentiation into fibre types. ${ }^{2}$ There is evidence to suggest that muscles of children with Duchenne muscular dystrophy have properties that are thought to be characteristic of immature muscle (for review see reference 3). Prolonged contraction and relaxation times have been reported,,$^{4-7}$ the ability of the sarcoplasmic reticulum to take up $\mathrm{Ca}^{2+}$ is $\operatorname{low}^{89}$ and the enzyme patterns retain immature characteristics. ${ }^{10}$ It has been suggested that a fundamental genetically determined defect occurs in dystrophic muscle which results in a slow rate of maturation of the muscle fibres, ${ }^{3}$ and that irreversible damage might be caused when the fast motoneurons activating these muscle fibres develop high frequency firing patterns. ${ }^{11}$

The possibility that the rate of muscle maturation can be enhanced by superimposing slow frequency activity has been investigated in animal models of muscular dystrophy. Improvement in function and a reduced loss of muscle fibres together with raised lev-

Address for reprint requests: Dr OM Scott, Physiotherapy
Department, Hammersmith Hospital, Du Cane Road, London,
W120HS, UK

Received 11 July 1985 and in revised form 14 January 1986. Accepted 15 February 1986 els of oxidative enzymes were observed in dystrophic mice following chronic stimulation. ${ }^{1213}$ Electrical stimulation was shown to induce enzyme and membrane properties characteristic of adult fast muscle ${ }^{14}$ and has also been shown to reduce the rate of deterioration of muscle fibres in dystrophic mice and chickens. ${ }^{1415}$ Muscle fibre regeneration is known to occur in Duchenne muscular dystrophy muscles ${ }^{16}$ and appropriate superimposed activity may induce maturation of existing muscle fibres and favour survival of newly regenerated muscle fibres possibly preventing subsequent degeneration. ${ }^{1415}$

\section{Subjects}

Sixteen boys with an established diagnosis of Duchenne muscular dystrophy, based on a clinical history of early onset and progressive weakness and confirmed by grossly raised levels of serum creatine kinase (CK) and muscle biopsy, participated in these investigations, which were approved by the Committee on Ethics of Clinical Investigations at Hammersmith Hospital. All the boys were attending the Muscle Clinic for regular 3-6 monthly reviews and were monitored in the Physiotherapy Department by recording their muscle strength and physical capabilities. ${ }^{17}$ Their ages on initial assessment ranged from 5-12 years (mean age 7.8 years). Twelve of the boys were still able to walk independently, two needed assistance to walk and two were confined to wheelchairs. Fourteen of the 16 boys volunteered for stimulation of their tibialis anterior muscle. The study of the effect of 
Table 1 Comparison of mean values $\pm S D$ of $M V C$, fatigue indices and ratios 10/40 and 20/40 Hz before and after fatigue testing of tibialis anterior in 16 children with DMD and 18 normal children.

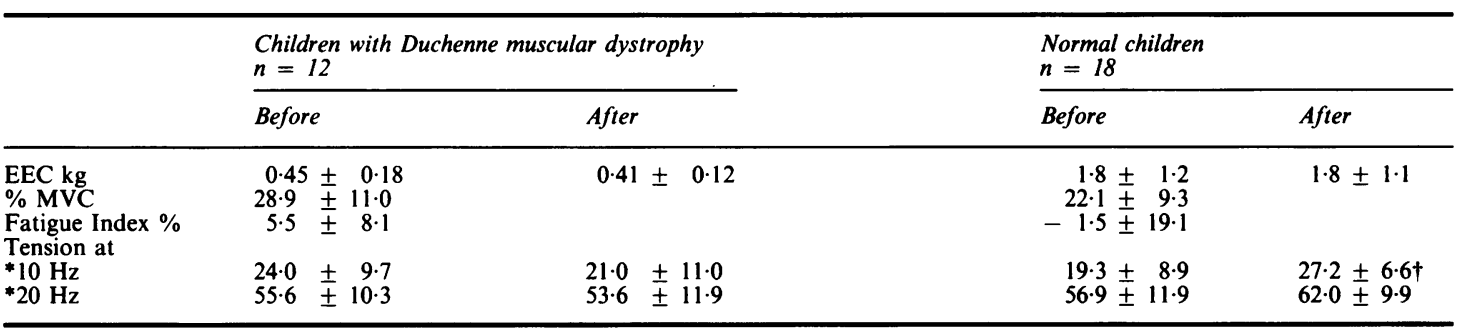

EEC - electrically elicited contraction at $40 \mathrm{~Hz}$.

* - tension expressed as \% of tension developed at $40 \mathrm{~Hz}$.

A Student's $t$ test (two tailed) for paired values was performed on the pre and post fatigue test data.

tp $<0.01$.

chronic low frequency stimulation was divided into two stages.

\section{Stage 1 Feasibility Study}

Eight boys took part in an initial feasibility study, to evaluate the parameters of stimulation and to identify any changes in the mechanical properties of the stimulated muscles. The subjects stimulated their muscles with a small battery operated stimulator at frequencies ranging from $5 \mathrm{~Hz}$ to $8 \mathrm{~Hz}$ continuously for an hour, three times daily for periods ranging from 7 to 10 weeks. Of the four older boys ranging in age from 10 to 11.9 years, two were confined to wheelchairs, one walked with the assistance of knee-ankle-foot orthoses and one walked with the assistance of a helper. The other four boys, aged from 5 to $7 \cdot 5$ years, were all still fully ambulant and could climb stairs (see later in table 3 ).

\section{Stage 2}

Analysis of the data obtained from the feasibility study indicated that there was some increase in maximum voluntary contraction (MVC) in the muscles of the younger boys who were in the early stage of the disease process. Therefore, subjects selected for the second stage of the study were all still able to walk independently and had not more than $20^{\circ}$ of fixed equinus deformity of the feet. The pattern of chronic stimulation was changed from continuous low frequency stimulation to intermittent stimulation (cycle $1.5 \mathrm{~s}$ on, $1.5 \mathrm{~s}$ off).

\section{Methods}

\section{Physical assessment}

The routine assessment of muscle strength and physical capabilities included evaluation of total muscle strength; $\% \mathrm{MRC}$, based on the clinical assessment of strength of 32 muscle groups; the force of eight skeletal muscle groups using an electromyometer; a motor ability score based on 20 consecutive motor activities; walking times measured over 28 feet and 150 feet; and recording of muscle contractures as described by Scott et al. ${ }^{17}$

\section{Muscle function studies}

Isometric tension recordings were made of maximum voluntary and electrically evoked contractions of the tibialis ante- rior muscle using a specially designed chair, a rigid foot plate and an adjustable padded steel bar which could be carefully aligned with the head of the first metatarsal. ${ }^{18}$ The subject was asked to make maximal effort to dorsiflex the foot against the bar and the output from strain gauges mounted on the bar was amplified and simultaneously recorded on an oscilloscope and a pen recorder. The deflection of the oscilloscope beam was observed by the subject and three, 1 to 3 second, maximum voluntary contractions were recorded. Unless the third was greatest, a fourth and if necessary further attempts were made until a maximum was achieved. Muscle contractions were also elicited by electrical stimulation using two $4 \mathrm{~cm}$ square carbon rubber electrodes, one placed proximally over the motor point and the other more distally on the belly of the muscle. A standardised sequence of testing was used to record the increase in tension in response to $250 \mathrm{~ms}$ of stimulation at $1,10,20$ and $40 \mathrm{~Hz}$. The ratios

and

$\frac{\text { tension }(10 \mathrm{~Hz})}{\text { tension }(40 \mathrm{~Hz})}$

$$
\text { tension }(20 \mathrm{~Hz})
$$$$
\text { tension }(40 \mathrm{~Hz})
$$

were determined.

The resistance to fatigue was determined by stimulating the muscle at $40 \mathrm{~Hz}$ for $250 \mathrm{~ms}$ every second for 5 minutes and a fatigue index,

$(F I)=\frac{\text { initial tension }- \text { tension after } 3 \text { minutes stimulation }}{\text { initial tension }}$.

was calculated.

The effect of the fatigue test was determined by recording the tension developed at $1,10,20$ and $40 \mathrm{~Hz}$ before and after fatigue and by monitoring the time course of contraction throughout the test. The following indices were recorded: peak tension at $40 \mathrm{~Hz}(\mathrm{Po})$ and the time to fall to $50 \%$ of peak tension $\left(1 / 2 \mathrm{RT}_{40}\right)$.

\section{Chronic low frequency stimulation}

The subjects stimulated their tibialis anterior muscles with a small battery operated stimulator at a frequency of $5-10 \mathrm{~Hz}$ for an hour three times daily for periods ranging from 7 to 11 weeks (mean 8.7 weeks). Stimulation was effected using 


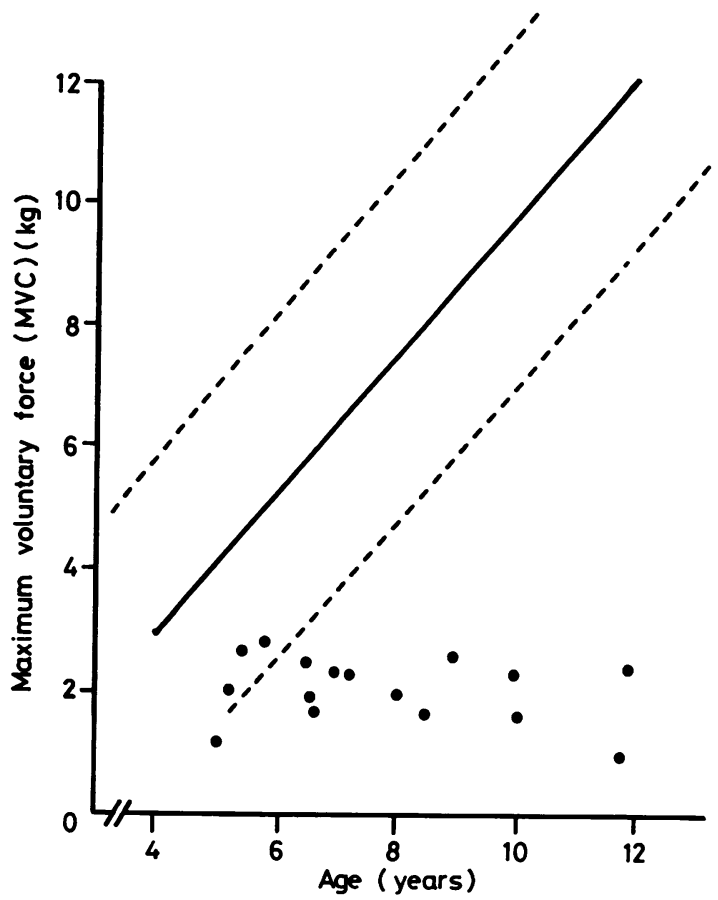

Fig 1 Relationship of maximum voluntary contraction $(M V C)$ of dorsiflexors of the ankle of children with Duchenne muscular dystrophy (DMD) with age: $a$ comparison is made of the same relationship of strength and age in normal children. Lines shown are the regression line (-) and the $95 \%$ confidence limits (---) for normal children from Scott et al. ${ }^{19}$

$4 \mathrm{~cm}$ square carbon electrodes placed on the tibialis anterior muscle in the same position as during the testing procedure. The electrodes were attached by leads to the stimulator concealed under the trousers and the stimulator was worn on a belt around the waist. The tension developed by this stimulator was comparable to that elicited at $10 \mathrm{~Hz}$ during the testing procedure and was approximately $25 \%$ of the max- imum force developed by the muscle at $40 \mathrm{~Hz}$. Each subject kept a day by day chart of hours of stimulation. Initial base line data of the mechanical properties of the tibialis anterior muscle were established for each subject from assessments on at least two separate occasions prior to commencing long term stimulation. Further testing was undertaken at regular 2-3 weekly intervals of stimulation and at monthly intervals following completion of stimulation. Muscles of the contralateral legs were also tested and acted as controls. The assessor did not know whether the right or left tibialis anterior muscle had been selected for long-term stimulation.

\section{Results}

\section{MUSCLE FUNCTION STUDIES IN DUCHENNE} MUSCULAR DYSTROPHY CHILDREN

Maximum voluntary contraction ( $M V C$ )

In contrast to previous findings in normal children ${ }^{18}$ muscle strength of children with Duchenne muscular dystrophy does not increase with age. Figure 1 compares the MVC exerted by the ankle dorsiflexor muscles of the 16 children with Duchenne muscular dystrophy with that of 18 normal children; the force increases with age whereas in Duchenne children a slight decrease is seen. There was little difference between the MVC exerted by the left or right leg (mean difference $=0.39 \mathrm{~kg} \pm 0.23$ ). Figure 1 also shows that in younger children with Duchenne muscular dystrophy, the MVC is within the range of the lower limits of normal strength.

\section{Electrically elicited responses}

Table 1 shows that about $29 \%$ of the MVC was activated by electrical stimulation at $40 \mathrm{~Hz}$. Comparison was made with the values obtained from a group of normal healthy children, aged 3-13 years, (mean age $=8 \cdot 3$ years). ${ }^{18}$

It can be seen that as in the muscles of normal children, there was a minimal loss of tension sustained in response to the fatigue test and there was no change of tension on re-stimulation at $40 \mathrm{~Hz}, 2-3$ minutes

Table 2 Comparison of mean values $\pm S D$ of peak tension and half relaxation times during fatigue testing of 12 children with Duchenne muscular dystrophy and 12 normal children.

$\begin{array}{ll}\text { Children with Duchenne muscular dystrophy } & \begin{array}{l}\text { Normal children } \\ n=12\end{array} \\ n=12\end{array}$

\begin{tabular}{lc}
$\begin{array}{l}\text { On initial stimulation }(40 \mathrm{~Hz}) \\
\% \text { MVC }\end{array}$ & $21 \cdot 0 \pm 6 \cdot 8$ \\
Peak Tension $(P o) \mathrm{kg}$ & $0 \cdot 4 \pm 0 \cdot 12$ \\
Relaxation time $\left(1 / 2 \mathrm{RT}_{40}\right) \mathrm{ms}$ & $153 \pm \pm 19 \cdot 1^{*}$ \\
$\begin{array}{l}\text { After } 3 \text { minutes of stimulation }(40 \mathrm{~Hz}) \\
\% \mathrm{MVC}\end{array}$ & $21 \pm 7 \cdot 6$ \\
$\begin{array}{l}\text { Po } \mathrm{kg} \\
1 / 2 \mathrm{RT}_{40} \mathrm{~ms}\end{array}$ & $0 \cdot 4 \pm 0 \cdot 16$ \\
\hline
\end{tabular}

$$
\begin{array}{cc}
20 & \pm 8.1 \\
1.5 & \pm 0.8 \\
103 & \pm 11.1 \\
& \\
20 & \pm 10.5 \\
1.5 & \pm 0.8 \\
113 & \pm 18.5
\end{array}
$$

${ }^{*} \mathrm{p}<0.001$.

A Student's $t$ test (two-tailed) for paired values was performed. 
Table 3 Physical assessment of 14 children with Duchenne muscular dystrophy on entry to study of effects of chronic low frequenc electrical stimulation and then six months later. Stage 1 refers to initial feasibility study; Stage 2 to the second study, see text

\begin{tabular}{|c|c|c|c|c|c|c|}
\hline Case & $\begin{array}{l}\text { Age on entry } \\
\text { (Years) }\end{array}$ & $\begin{array}{l}\text { Period of } \\
\text { stimulation } \\
\text { (Weeks) }\end{array}$ & $\begin{array}{l}\text { Functional ability } \\
\text { (Vignos) }\end{array}$ & $*$ & $\% M R C$ & $*$ \\
\hline \multicolumn{7}{|l|}{ Stage 1} \\
\hline & 11.9 & 11 & 9 & 9 & 47 & 50 \\
\hline 2 & 10 & 10 & 6 & 6 & 49 & 46 \\
\hline 3 & 11 & - & 9 & - & 44 & - \\
\hline 4 & 11.7 & - & 5 & - & 47 & - \\
\hline 5 & 7.5 & 8 & 2 & 2 & 80 & 63 \\
\hline 6 & 5.9 & 10 & 2 & 2 & 63 & 53 \\
\hline 7 & $5 \cdot 5$ & 7 & 2 & 2 & 73 & 66 \\
\hline 8 & $5 \cdot 0$ & 9 & 2 & 2 & 62 & 60 \\
\hline Mean & 7.63 & $9 \cdot 2$ & 3.83 & $3.83^{*}$ & 62 & $56^{*}$ \\
\hline \pm SD & $2 \cdot 77$ & 1.47 & 2.99 & 2.99 & 13 & 8 \\
\hline$\underset{9}{\text { Stage } 2}$ & $10 \cdot 0$ & 10 & 3 & 3 & & 46 \\
\hline 10 & $\begin{array}{r}10.0 \\
8.5\end{array}$ & $\begin{array}{r}10 \\
9\end{array}$ & & 2 & 65 & $\begin{array}{l}40 \\
61\end{array}$ \\
\hline 11 & $7 \cdot 2$ & 10 & 2 & 2 & 63 & 57 \\
\hline 12 & 6.7 & 7 & 3 & 3 & 57 & 52 \\
\hline 13 & $5 \cdot 5$ & 7 & 3 & 2 & 69 & 60 \\
\hline 14 & $5 \cdot 3$ & 9 & 2 & 2 & 72 & 68 \\
\hline Mean & $7 \cdot 2$ & $8 \cdot 7$ & $2 \cdot 5$ & $2 \cdot 3^{*}$ & 64 & $57^{*}$ \\
\hline $\pm S D$ & 1.8 & 1.4 & 0.6 & 0.5 & 6 & 8 \\
\hline
\end{tabular}

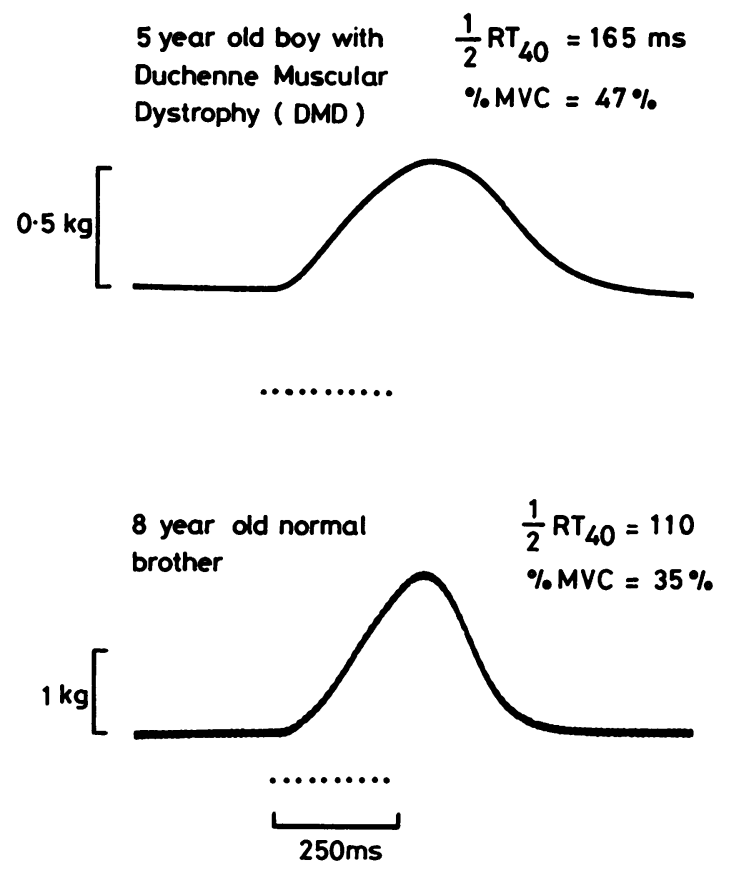

Fig 2 Time course of muscle contraction of the tibialis anterior muscle of a 5-year-old boy with Duchenne muscular dystrophy (DMD) and that of his normal 8-year-old brother on stimulation for $250 \mathrm{~ms}$ at $40 \mathrm{~Hz} . \% M V C=\%$ of maximum voluntary contraction, $1 / 2 R T_{40}=$ time to fall to $50 \%$ of peak tension. later. Table 1 compares the proportion of tension developed at 10 and $20 \mathrm{~Hz}$ expressed as a percentage of the tension at $40 \mathrm{~Hz}$; in the dystrophic muscles, these ratios remained unaltered after the fatigue test whereas the muscles of normal children showed postfatigue potentiation at the lower frequencies of stimulation.

Table 2 summarises the results of monitoring the time course of relaxation before and after fatigue testing of 12 children with Duchenne muscular dystrophy. At the start of the fatigue test the mean half relaxation time was $153 \mathrm{~ms} \pm 19 \cdot 1$ and there was little variation in the time course of contraction and relaxation during the fatigue test. Comparison with the values obtained from a group of normal healthy children $^{19}$ showed that the relaxation time is very significantly slower $(p<0.001)$ in the muscles of children with Duchenne muscular dystrophy. Figure 2 illustrates the different responses to stimulation at $40 \mathrm{~Hz}$ of the muscles of a five year old boy with Duchenne muscular dystrophy and that of his eight year old normal brother.

\section{Effects of chronic low frequency stimulation}

Six of the eight boys who took part in the feasibility study tolerated the stimulators well, operated the controls themselves and had excellent records of compliance with the planned programme of chronic stimulation. Two of the older boys with marked equinus deformities experienced technical problems associated with the stimulator and their results were not included in the final analysis. In one case, it was very doubtful 


\begin{tabular}{|c|c|c|c|c|c|c|c|}
\hline \multirow{2}{*}{\multicolumn{2}{|c|}{$\begin{array}{l}\text { Motor ability score } \\
(\text { Total }=40)\end{array}$}} & \multicolumn{4}{|c|}{ Equinus deformity } & \multirow{2}{*}{$\begin{array}{l}\text { Walking time } \\
\text { (28 feet) } \\
\text { (Sec) }\end{array}$} & \multirow[b]{2}{*}{$*$} \\
\hline & & Control & ${ }^{*}($ degrees $)$ & Stimulated & $*$ & & \\
\hline \multicolumn{8}{|l|}{$=$} \\
\hline 13 & 13 & 50 & 45 & 45 & 40 & - & - \\
\hline 13 & 12 & 35 & 40 & 35 & 35 & 25 (in calipers) & 44 \\
\hline 17 & $\ldots$ & 50 & - & 45 & - & - & - \\
\hline 10 & $\overline{2}$ & 30 & $\overline{20}$ & 25 & $\bar{n}$ & - & - \\
\hline-32 & 34 & 10 & 25 & 10 & 20 & 4 & 6 \\
\hline 34 & 28 & 20 & 20 & 15 & 20 & 5 & 7 \\
\hline 34 & 34 & 20 & 20 & 20 & 25 & $4 \cdot 5$ & 4 \\
\hline 30 & 32 & 15 & 20 & 20 & 20 & 8 & 5 \\
\hline 26 & $\begin{array}{l}25 \cdot 5^{*} \\
10 \cdot 3\end{array}$ & $25 \cdot 0$ & $28 \cdot 3^{*}$ & $24 \cdot 2$ & $26 \cdot 7^{*}$ & $9 \cdot 3$ & $13 \cdot 2^{*}$ \\
\hline$\sqrt{0 \cdot 2}$ & $10 \cdot 3$ & $14 \cdot 8$ & $11 \cdot 3$ & $13 \cdot 2$ & $8 \cdot 75$ & 8.91 & $17 \cdot 3$ \\
\hline 28 & 24 & 20 & 20 & 20 & 15 & $7 \cdot 5$ & 9 \\
\hline $\begin{array}{l}36 \\
34\end{array}$ & 32 & 23 & 25 & 25 & 25 & 4 & 4 \\
\hline $\begin{array}{r}34 \\
31\end{array}$ & $\begin{array}{l}36 \\
25\end{array}$ & $\begin{array}{l}20 \\
25\end{array}$ & $\begin{array}{l}20 \\
25\end{array}$ & $\begin{array}{l}20 \\
25\end{array}$ & $\begin{array}{l}20 \\
35\end{array}$ & $\begin{array}{l}4 \\
6\end{array}$ & $5 \cdot 5$ \\
\hline 31 & 34 & 20 & 20 & $\begin{array}{l}25 \\
20\end{array}$ & $\begin{array}{l}35 \\
20\end{array}$ & $\begin{array}{l}6 \\
4\end{array}$ & $\begin{array}{l}8 \\
4\end{array}$ \\
\hline 36 & 32 & 20 & 28 & 20 & 28 & 3 & 4 \\
\hline 32.7 & $30 \cdot 5^{*}$ & $21 \cdot 3$ & $23 \cdot 0^{*}$ & $21 \cdot 7$ & $23 \cdot 8^{*}$ & 4.75 & $5.75^{*}$ \\
\hline $3 \cdot 2$ & $4 \cdot 9$ & $2 \cdot 2$ & $3 \cdot 5$ & $2 \cdot 6$ & $7 \cdot 1$ & 1.7 & 2.2 \\
\hline
\end{tabular}

if a palpable force output had been sustained when the boy stimulated his muscle and in the second case, it was only possible to obtain effective stimulation by very careful positioning of the electrodes and this proved to be impractical on a long-term basis.

Six boys took part in Stage 2 of the study; all boys sustained excellent records of compliance with the planned programme of stimulation. Table 3 shows that in both studies, the periods of stimulation, $9 \cdot 2$ weeks \pm 1.47 and 8.7 weeks \pm 1.36 were comparable and the mean ages, 7.6 years \pm 2.76 years and 7.2 years \pm 1.8 years of the children similar, although the range of ages in the first group was greater.

Table 3 summarises the background data of all the 14 boys who took part in the study of the effect of low frequency stimulation. On reassessment 6 months later, an overall deterioration in their physical characteristics was apparent. Analysis of co-variance of the results of the 10 younger ambulant subjects showed a highly significant decrease $(p<0.01)$ of overall muscle strength (\%MRC) which did not correlate with the motor ability score, slowing of the independent walking times by $0.65 \mathrm{~s} \pm 1.58$ and a variable but in most cases symmetrical deterioration of the ankle equinus deformities.

Comparison of the mean values of MVC of the stimulated muscles and the unstimulated contralateral controls during the 8 weeks of Stage 2 of the study are shown in fig 3 . There was no significant change in MVC in the chronically stimulated muscles of the older boys who took part in Stage 1 of the study. In contrast the MVC of the younger boys selected for
Stage 2 showed a mean increase of $47 \%$. Figure 3 shows no change of MVC was apparent during the first six weeks of chronic stimulation but in five out of the six subjects an increase of MVC occurred after 6 weeks. The stimulated muscles showed a small but significant increase in strength of $0.7 \mathrm{~kg} \pm 0.64$

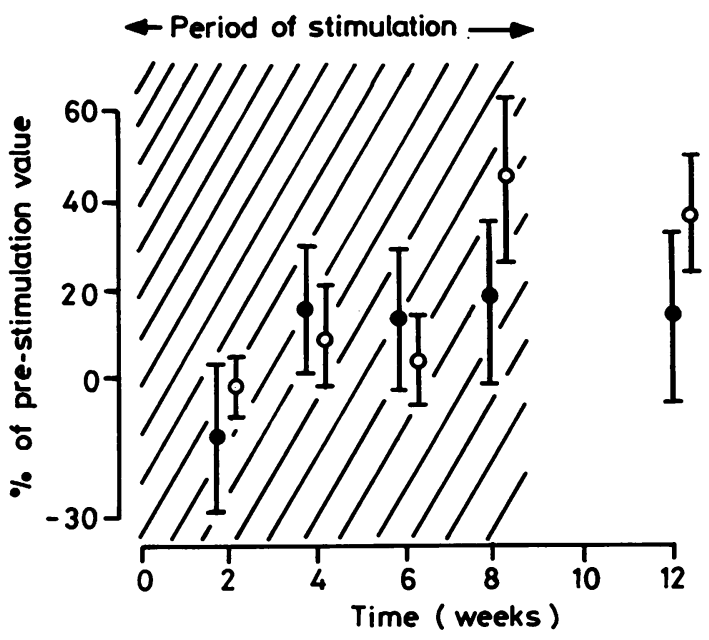

Fig 3 Force of maximum voluntary contraction ( $M V C$ ) expressed as a \% of initial values, before the start of stimulation of the control ( $)$ and electrically stimulated $(\bigcirc)$ muscles of the six boys with Duchenne muscular dystrophy in stage 2 of the study. Each point represents the mean value $\pm S E$ of mean. 
Table 4 Relaxation times after 3 minutes of stimulation at $40 \mathrm{~Hz}$ of 10 boys with Duchenne muscular dystrophy before and after chronic low frequency stimulation

\begin{tabular}{|c|c|c|c|c|c|c|c|}
\hline \multirow[b]{3}{*}{ Case } & \multirow{3}{*}{$\begin{array}{l}\text { Age } \\
\text { (years) }\end{array}$} & \multirow{2}{*}{\multicolumn{2}{|c|}{ Stimulation }} & \multicolumn{4}{|c|}{ Relaxation time $\left(1 / 2 R T_{40}\right) \mathrm{ms}$} \\
\hline & & & & \multicolumn{2}{|c|}{ Control leg } & \multicolumn{2}{|c|}{ Stimulated leg } \\
\hline & & Weeks & Frequency $(\mathrm{Hz})$ & Before & After & Before & After \\
\hline $\begin{array}{c}\text { Stage } 1 \\
5^{*} \\
6 \\
7 \\
8\end{array}$ & $\begin{array}{l}7 \cdot 5 \\
5 \cdot 9 \\
5 \cdot 5 \\
5 \cdot 0\end{array}$ & $\begin{array}{r}8 \\
10 \\
7 \\
9\end{array}$ & $\begin{array}{l}7 \\
8 \\
8 \\
5\end{array}$ & $\begin{array}{l}110^{*} \\
152 \\
152 \\
140\end{array}$ & $\begin{array}{l}110^{*} \\
159 \\
165 \\
171\end{array}$ & $\begin{array}{l}110^{*} \\
152 \\
146 \\
165\end{array}$ & $\begin{array}{l}122^{*} \\
152 \\
140 \\
142\end{array}$ \\
\hline $\begin{array}{l}\text { Stage } 2 \\
9 \\
10 \\
11 \\
12 \\
13^{*} \\
14^{*} \\
\text { Mean } \\
\pm \text { SD }\end{array}$ & $\begin{array}{r}10.0 \\
8.5 \\
7.2 \\
6.7 \\
6.5 \\
5.3\end{array}$ & $\begin{array}{r}10 \\
9 \\
10 \\
7 \\
7 \\
9\end{array}$ & $\begin{array}{l}8 \\
6 \\
8 \\
6 \\
6 \\
6\end{array}$ & $\begin{array}{c}143 \\
155 \\
146 \\
134 \\
98^{*} \\
110^{*} \\
134 \\
20.5\end{array}$ & $\begin{array}{c}146 \\
140 \\
171 \\
122 \\
122^{*} \\
100^{*} \\
141 \\
26.0\end{array}$ & $\begin{array}{l}146 \\
134 \\
149 \\
146 \\
110^{*} \\
113^{*} \\
137 \\
19.5\end{array}$ & $\begin{array}{c}152 \\
122 \\
152 \\
152 \\
98^{*} \\
122^{*} \\
135 \\
18 \cdot 6\end{array}$ \\
\hline
\end{tabular}

*Denotes faster half relaxation times throughout the experimental period (see text).

$(\mathrm{p}<0.05)$ compared with $0.2 \mathrm{~kg} \pm 0.84$ increase of strength of the control muscles at week 8 and were still significantly stronger than the unstimulated control muscles one month after completion of stimulation.

The unstimulated muscles showed no significant change in MVC but the plot of the percentage change of MVC in these muscles revealed an initial tendency to decrease at 2 weeks followed by an overall increase for the remaining 6 weeks suggesting a possible contralateral training effect which was still present on retesting a month later.

There was no change in the fatigue indices after chronic low frequency stimulation in Stage 1 or 2 of the study; both the control and stimulated muscles were able to maintain the initial tension evoked during the five minutes of stimulation at $40 \mathrm{~Hz}$. Mean maximal forces of $0.4 \mathrm{~g} \pm 0.21(23 \%$ of MVC) were sustained on initial assessment by the tibialis anterior muscles of both legs and comparable forces of $0.5 \mathrm{~kg}$ $\pm 0.2(24 \%$ of MVC) were maintained on reassessment at the end of the study.

Analysis of the tensions developed in response to brief trains of stimulation at 10 and $20 \mathrm{~Hz}$ before and after the fatigue test and expressed as the percentage of tension evoked at $40 \mathrm{~Hz}$ showed no apparent changes in these ratios following prolonged low frequency stimulation.

The values obtained for the half-relaxation times after 3 minutes of fatigue testing at $40 \mathrm{~Hz}$ for both control and chronically stimulated muscles are summarised in table 4 . The relaxation times were unchanged throughout the fatigue test or on restimulation after completion of the test indicating that there had been no apparent change in the contractile properties of the muscles in response to prolonged low frequency stimulation. Three boys (cases 5, 13 and 14) aged $7 \cdot 5,6 \cdot 5$ and $5 \cdot 3$ years respectively showed consistently faster relaxation times comparable with the values established for normal children (table 4). These children also had high scores of total muscle strength.

\section{Discussion}

In normal children, muscle strength increases with age; this relationship is not sustained in children with Duchenne muscular dystrophy. The results of the first part of the study showed low values of maximum voluntary contraction (MVC) of the youngest boys (4-6 years) and a slight decrease of these force levels in older children. Comparable values of maximum strength for the ankle dorsiflexors have been found in previous studies. ${ }^{41719}$

Maximal contraction of tibialis anterior was elicited on stimulation at $40 \mathrm{~Hz}$ with minimal cross stimulation of extensor digitorum longus or other synergistic muscles.

The procedure was well tolerated by the children who, although very apprehensive on initial assessment, rapidly became familiar with the procedure and gained confidence that there was no pain or discomfort associated with the tests. The $29 \%$ of MVC (table 1) elicited by stimulation was comparable to the mean value of $22 \%$ evoked in the muscles of normal children. In absolute values however, the electrically elicited contractions were only about a third of those from muscles of normal children, reflecting the weakness of dystrophic muscles.

Normal children's muscle, although showing no loss of tension during the fatigue test, showed significant force potentiation $(p<0.01)$ on restimulation at $10 \mathrm{~Hz}$ within 2-3 minutes of completion of the test (table 1). The muscles of children with 
Duchenne muscular dystrophy demonstrated a similar ability to maintain tension during the test but after the test on re-stimulation at low frequencies there was no post fatigue increased force output.

The ability of children's muscles to maintain tension contrasts with the decline of force observed in normal mature adult muscle during the fatigue test and is probably associated with a more efficient supply of oxygen resulting from the smaller diameters of children's muscle fibres. ${ }^{18}$ Roe and his colleagues ${ }^{20}$ found that the muscles of children with Duchenne muscular dystrophy were very difficult to fatigue. The lack of post fatigue force potentiation suggests that the mechanism by which the onset of fatigue is prevented may be different in dystrophic muscles from that in normal children's muscle.

Previous studies of fatigue, (for review see reference 21) emphasise the close association between loss of tension and longer relaxation times. This present study demonstrates maintenance of tension together with minimal changes of relaxation time throughout the 5 minute test or on retesting within 5 minutes of completing the test and confirms our clinical impression that these children have an ability to sustain functional activities albeit at low levels of force output.

It was Duchenne ${ }^{22}$ who first suggested that electrical stimulation of diseased muscle might be beneficial to patients with muscular dystrophy and yet no consistent trials were carried out using electrical stimulation in any neuromuscular disease. The use of electrical stimulation may have seemed superfluous particularly in those conditions such as Duchenne muscular dystrophy where muscles can be activated voluntarily and more or less normal patterns of their EMG can be recorded. ${ }^{23}$ Thus, to evaluate the effect of muscle activity on the progress of the disease, different exercise regimes were applied, rather than electrical stimulation. ${ }^{24}$

In recent years a number of studies have shown that the properties of skeletal muscle fibres are greatly influenced by the activity pattern they receive, no matter whether this activity is delivered to the muscle by its motoneuron, or by electrical stimulation. ${ }^{25}$ It is also known that during voluntary movement the pattern of activity delivered to the muscle depends on constraints given by the control mechanisms of the central nervous system that regulates movement. ${ }^{26}$

An attempt was made in this study to bypass the CNS and impose onto muscles of patients with Duchenne muscular dystrophy a particular activity pattern using electrical stimulation. In view of some "immature" features of muscles of Duchenne muscular dystrophy patients, such as slow time course of contraction and relaxation, and reduced ability of their sarcoplasmic reticulum to take up $\mathrm{Ca}^{2+}$, a low frequency activity pattern was used, typical of firing pat- terns recorded from muscles of immature animals. ${ }^{11}$

The present results show that muscles of children suffering from Duchenne muscular dystrophy can be influenced by chronic low frequency stimulation, provided that the stimulation is applied at a time when the children are not yet severely disabled. This beneficial effect of chronic stimulation could be due $(a)$ to slower deterioration of the existing diseased muscle fibres, $(b)$ to a better and more rapid growth of regenerating fibres that are known to be present in muscles from Duchenne muscular dystrophy children, particularly in the younger age groups, or $(c)$ to hypertrophy of existing relatively healthy fibres. From the present information it is impossible to decide which of these possibilities makes the greatest contribution to the improved performance. It is well established that low frequency stimulation leads to a slight decrease, rather than increase of muscle fibre diameters ${ }^{27}$ so that this type of activity is unlikely to induce hypertrophy in normal muscle fibres yet dystrophic muscle may behave differently. The finding that none of the other properties of dystrophic muscle was altered by chronic electrical stimulation was not surprising. This type of stimulation was shown to increase fatigue resistance in adult muscles. However as normal children's muscles and those of children with Duchenne muscular dystrophy showed no loss of tension during the fatigue test, superimposed low frequency stimulation could not be expected to change already fatigue resistant muscles.

The lack of change of contractile characteristics using low frequency activity favours the development and maintenance of "slow" type muscle characteristics, and this may be the overriding effect of this treatment. The increase of the MVC in the stimulated muscles was considerable, particularly in view of the fact that only a proportion of the muscle was stimulated. However it may be that the enhanced activity of part of the muscle has a beneficial effect on the whole muscle group.

The results are encouraging and further studies are necessary to investigate the effect of different patterns of electrical activity and to monitor the effect of stimulation on other muscle groups. The acceptability of the method of electrical stimulation has been clearly demonstrated and, if the results of further studies support the findings reported here, the techniques may possibly have therapeutic applications.

We are grateful to the Medical Research Council for supporting this work, to Biomedical Research Limited for supplying some stimulators and to the families who participated in the study.

\section{References}

1 Perry SV, Dhoot GK. Biochemical aspects of muscle 
development and differentiation. In: Goldspink DF, ed. Development and Specialisation of skeletal muscle. Cambridge: Cambridge University Press, 1985:51-64.

2 Dubowitz V. Developing and Diseased muscle: a Histochemical Study. London: Heinemann, 1968.

3 Vrbová G. Duchenne dystrophy viewed as a disturbance of nerve-muscle interactions. Muscle Nerve 1983;6:671-5.

4 Botelho SY, Beckett MS, Bendler E. Mechanical and electrical responses in intact thenar muscles to indirect stimuli. Study of patients with pseudohypertrophic muscular dystrophy. Neurology 1960;10:601-12.

5 Desmedt JE, Emeryk B. Disorder of muscle contraction processes in sex-linked (Duchenne) Muscular Dystrophy with correlative electromyographic study of myopathic involvement in small hand muscles. Am J Med 1968;45:853-72.

6 Buchtal F, Schmalbruch H, Kamieniecka Z. Contraction times and fibre types in patients with progressive muscular dystrophy. Neurology 1971;21:131-9.

7 McComas AJ, Sica REP, Currie S. An electrophysiological study of Duchenne dystrophy. J Neurol Neurosurg Psychiatry 1971;34:461-8.

8 Sreter FA, Ikemoto M, Gergely J. Studies on the fragmented sarcoplasmic reticulum of normal and dystrophic mouse muscle. In: Milhorat AT, ed. Exploratory Concepts in Muscular Dystrophy and Related Disorders. Amsterdam: Excerpta Medica Foundation, 1967:289-98.

9 Samaha FJ, Gergely J. Biochemical abnormalities of the sarcoplasmic reticulum in muscular dystrophy. $N$ Engl J Med 1969;280:184-8.

10 Perry SV. Development and specialisation in muscle and the biochemistry of the dystrophies. J Neurol Sci 1971;12:289-306.

11 Navarette R, Vrbová G. Changes of activity patterns in slow and fast muscles during postnatal development. Developmental Brain Research 1983;8:11-9.

12 Luthert P, Vrbová G, Ward KM. Effects of slow frequency electrical stimulation on muscles of dystrophic mice. J Neurol Neurosurg Psychiatry 1980;43:803-9.

13 Vrbová G, Ward K. Observations on the effects of low frequency electrical stimulation on fast muscles of dystrophic mice. J Neurol Neurosurg Psychiatry 1981;44:1002-6.

14 Reichmann H, Pette D, Vrbová G. Effects of low frequency electrical stimulation on enzyme and iso- enzyme patterns of dystrophic mouse. FEBS Lett 1981;128, 1:55-8.

15 Barnard EA, Barnard P, Jarvis JC, Lai J. Low frequency stimulation in vivo of chick fast-twitch muscle. J Physiol (London) 1984;351:37p.

16 Dubowitz V. Muscle Biopsy. A Practical Approach. London: Baillière Tindall 2nd Ed., 1973.

17 Scott OM, Hyde SA, Goddard C, Dubowitz V. Quantitation of muscle function in children: a prospective study in Duchenne Muscular Dystrophy. Muscle Nerve 1982;5:291-301.

18 Scott OM, Vrbová G, Hyde SA, Dubowitz V. Effects of chronic low frequency electrical stimulation on normal human tibialis anterior muscle. J Neurol Neurosurg Psychiatry 1985;48:774-81.

19 Fowler W, Gardiner G. Quantitative strength measurements in muscular dystrophy. Arch Phys Med Rehabil 1967:48:629-44.

20 Roe RD, Yamaji K, Sandow A. Contractile responses of dystrophic muscles of man and mouse. In: Milhorat AT, ed. Exploratory Concepts in Muscular Dystrophy and Related Disorders. Amsterdam: Excerpta Medica Foundation, 1967:299-304.

21 Bigland-Ritchie B, Woods JJ. Changes in muscle contractile properties and neural control during human muscular fatigue. Muscle Nerve 1984;7:691-9.

22 Duchenne GB. De l'electricisation localisée et son application à la pathologie et à la thérapeutique. Paris Bailliere et Fils. 2nd ed. 1972.

23 Scott OM, Hyde SA, Goddard G, Jones R, Dubowitz V. Effect of exercise in Duchenne Muscular Dystrophy. Physiotherapy 1981;67, 6:177-80.

24 Lenman JAR. Integration and analyses of the electromyogram and related techniques. In: Walters $\mathrm{J}$, ed. Disorders of Voluntary Muscle. 4th ed. Edinburgh: Churchill Livingston, 1980:976-1007.

25 Pette D, Vrbová G. Control of the Phenotype Expression in mammalian muscle fibres. Muscle Nerve 1985;8: 676-89.

26 Freund HJ. Motor Unit and Muscle Activity in Voluntary motor control. Physiol Rev 1983;63, 2:387-436.

27 Brown MD, Cotter MA, Hudlická O, Vrbová G. The effects of different patterns of muscle activity and capillary density, mechanical properties and structure of slow and fast rabbit muscles. Pflugers Arch 1976; 361:241-50. 